\title{
Comparison of Dermal Matrix and Polytetrafluoroethylene Membrane for Socket Bone Augmentation: A Clinical and Histologic Study
}

\author{
Paul D. Fotek, ${ }^{*}$ Rodrigo F. Neiva, ${ }^{\dagger}$ and Hom-Lay Wang ${ }^{\dagger}$
}

Background: Remodeling and resorption of the alveolar crest, specifically at the buccal aspect, characterize the healing extraction socket. These result in narrowing and shortening of the alveolar ridge, which compromise esthetics and complicate restoration. Alveolar ridge augmentation has been proposed to facilitate future site restoration by minimizing ridge resorption. Therefore, the purpose of this study was to compare extraction socket healing and alveolar ridge alteration after socket augmentation using bone allograft covered with an acellular dermal matrix (ADM) or polytetrafluoroethylene (PTFE) membrane.

Methods: Twenty non-smoking healthy subjects were selected. Each subject required maxillary premolar, canine, or central incisor tooth extraction. The extraction sites were debrided and grafted with a mineralized bone allograft that was covered with an ADM or PTFE membrane. Postoperative appointments were scheduled at 2, 4, and 8 weeks. After 16 weeks of healing, final measurements were performed, and trephine core biopsies were obtained for histomorphometric analysis. Implants were placed immediately after biopsy harvesting.

Results: Eighteen subjects completed the study. All sites healed without adverse events and allowed for implant placement. PTFE membranes exfoliated prematurely, with an average retention time of 16.6 days, whereas the ADM membranes appeared to be incorporated into the tissues. Buccal plate thickness loss was 0.44 and 0.3 $\mathrm{mm}$, with a vertical loss of 1.1 and $0.25 \mathrm{~mm}$, for ADM and PTFE, respectively. Bone quality assessment indicated D3 to be the most prevalent (61\%). Histomorphometric analysis revealed $41.81 \%$ versus $47.36 \%$ bone, $58.19 \%$ versus $52.64 \%$ marrow/fibrous tissue, and $13.93 \%$ versus $14.73 \%$ particulate graft remaining for ADM and PTFE, respectively. No statistical difference was found between the two treatment groups for any of the parameters.

Conclusion: All sites evaluated showed minimal ridge alterations, with no statistical difference between the two treatment modalities with respect to bone composition and horizontal and vertical bone loss, indicating that both membranes are suitable for alveolar ridge augmentation. J Periodontol 2009;80:776-785.

\section{KEY WORDS}

Bone regeneration; graft; membranes; preservation; socket; tooth extraction.

\footnotetext{
* Private practice, West Palm Beach, FL.

$\dagger$ Department of Periodontics and Oral Medicine, School of Dentistry, University of Michigan, Ann Arbor, MI.
}

$\square$ xtraction socket augmentation has been proposed as a means of controlling alveolar ridge degradation, preserving crestal buccal plate integrity, improving vital bone fill, and reducing the need for future ridge augmentation. ${ }^{1-5}$ Research has evaluated the use of membrane, bone grafts, and a combination of the two for controlling buccal plate loss. ${ }^{6-10} \mathrm{Nu}$ merous grafting materials, such as xenografts, allografts, and alloplasts, were studied along with wound dressing and bioabsorbable or non-resorbable membranes. Nevertheless, vertical and horizontal ridge dimension alterations were still evident.

The general understanding is that bone graft placed in the extraction socket should offset the catabolic processes observed within the crestal buccal plate region. The ideal bone graft should possess osteogenic, osteoinductive, and osteoconductive properties. Unfortunately, all of these are solely found within the autogenous graft that is available only in limited quantities, and its procurement is associated with substantial post-surgical morbidity. Xenografts have been used successfully and studied widely for various periodontal and implant-related

doi: 10.1902/jop.2009.080514 
surgeries ${ }^{11}$ because they are chemically and physically similar to the human bone mineral matrix. The major drawback of the material is its slow resorption, with graft particles present 44 months after placement. ${ }^{12}$ Alloplasts pose no risk for disease transmission because they are fabricated in the laboratory. ${ }^{13}$ Although their safety may be questioned with the recent history of procurement irregularities, the United States Food and Drug Administration and other investigators ${ }^{14-16}$ found them to be very safe, with no recorded occurrence of donor-recipient disease transmission. Fairly recently, a new solvent-preserved mineralized cancellous allograft was introduced, which was purported to have advantage over others that are widely used, including the ability to maintain its three-dimensional structure, organic matrix, and collagen content. This bone graft has been used for guided tissue regeneration, ${ }^{17,18}$ sinus elevation, ${ }^{19,20}$ guided bone regeneration, ${ }^{21}$ implant defect grafting, 22 and socket augmentation, $, 23,24$ with varying degrees of success.

The placement of wound dressing over the grafted extraction socket is critical in preventing bone graft loss. Numerous bioabsorbable and non-resorbable materials, along with various grafting techniques, have been used; they showed varying degrees of success with regard to graft retention. ${ }^{2,24-28}$ Some of the popular techniques include the mineralized bone allograft-plug socket augmentation technique, ${ }^{24}$ the Bio$\mathrm{Col}^{1}$ technique, and socket seal surgery ${ }^{29}$ using a free gingival graft and its modification using the connective tissue. ${ }^{30}$ To the best or our knowledge, there are no comparative studies evaluating the healing augmented extraction socket covered with a bioabsorbable membrane versus a non-resorbable membrane. Hence, the purpose of this study was to report on the clinical and histologic evidence after the use of two different membranes for socket bone augmentation.

\section{MATERIALS AND METHODS}

The University of Michigan Institutional Review Board governing the use of human subjects in clinical research approved this randomized, single-masked clinical trial. All patients underwent a screening process; written consent for clinical trial participation was obtained along with complete medical and dental history. Twenty consecutive subjects were recruited into the study from the patient pool at the University of Michigan between August 2006 and February 2007. Inclusion criteria were age $\geq 18$ years, systemic health, adequate band of keratinized tissue $(\geq 2 \mathrm{~mm})$, and at least one tooth in the maxillary central incisor, canine, or premolar region that needed to be extracted and replaced with an implant. Exclusion criteria were smoking; pregnancy or a planning to become preg- nant; unstable systemic diseases or chronic disorders precluding surgical procedures; compromised healing potential (e.g., uncontrolled diabetes or steroid use); osseous metabolic disorders (e.g., osteoporosis); inadequate bone height and width for future implant placement; teeth exhibiting periapical pathology or purulence (symptomatic); and allergy to medication used in the study.

Surgical guides were fabricated using malleable acrylic $^{\ddagger}$ during the presurgical phase; the guide was designed to rest on the occlusal surfaces of at least two teeth next to the tooth to be extracted. Over the extraction site, the model was trimmed to the gingival level to facilitate a reproducible vertical measurement from the mid-alveolar crestal to the coronal part of the surgical stent. The surgical stent was further modified with a buccal extension so that a reproducible horizontal measurement could be made $5.0 \mathrm{~mm}$ from the free gingival margin. The measurements were made at the mesial, mid-buccal, and distal line angle. Patients were randomly assigned to the acellular dermal matrix $(A D M) \S$ or polytetrafluoroethylene (PTFE) ${ }^{\|}$groups (Figs. 1 and 2). A radiographic positioning device ${ }^{\text {II }}$ was adapted with an aluminum step wedge $^{\#}$ on the maxillary side using hot glue, whereas a bite-registration material ${ }^{*}$ * was placed on the mandibular side of the device. This custom radiographic positioning device facilitated $\mathrm{x}$-ray reproducibility. A standardized periapical radiograph was taken using $\mathrm{F}$-speed ${ }^{\dagger \dagger}$ film with the radiographic positioning device.

Baseline data were collected prior to extraction. These included the patient's vital signs, probing depth $(\mathrm{PD})$, gingival index $(\mathrm{GI}),{ }^{31}$ plaque index $(\mathrm{PI}),{ }^{31}$ pain score, and keratinized gingiva (KG) width using a periodontal probe ${ }^{\ddagger}$ to 0.5 -mm accuracy. Minimally traumatic tooth extractions were performed. The socket was debrided, perforated using a quarter-round surgical bur, and rinsed with $0.9 \% \mathrm{NaCl}$ saline solution. Data were again recorded using a University of North Carolina (UNC) probe and the custom measuring stent. The measurements recorded were buccal plate to the stent at three predetermined points, the corresponding soft tissue thickness, and the mid-lingual soft tissue thickness $5 \mathrm{~mm}$ from the free gingival margin. Using a caliper, $§ \S$ the buccal plate and lingual plate thickness was measured at the same points as the previous measurements. Finally, the width of

\footnotetext{
* Triad, Dentsply International, York, PA.

$\S$ AlloDerm GBR membrane, BioHorizons, Birmingham, AL.

Cytoplast TXT-200, Osteogenics Biomedical, Lubbock, TX.

II XCP, Rinn, Elgin, IL.

\# Dr. Stanley M. Dunn, Neshanic Station, NJ.

** Blu-Bite HP, Henry Schein, Melville, NY.

$\dagger \dagger$ Kodak Insight, Eastman Kodak, Rochester, NY.

末 UNC probe, Hu-Friedy, Chicago, IL.

$\S \S$ Castroviejo caliper, Salvin Dental Specialties, Charlotte, NC.
} 


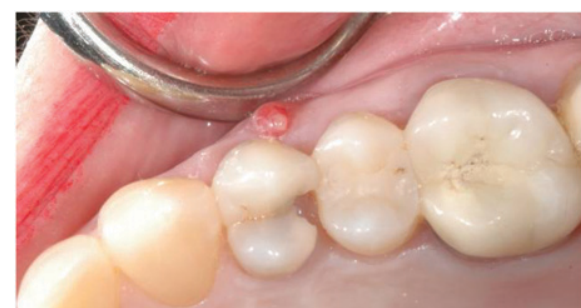

A
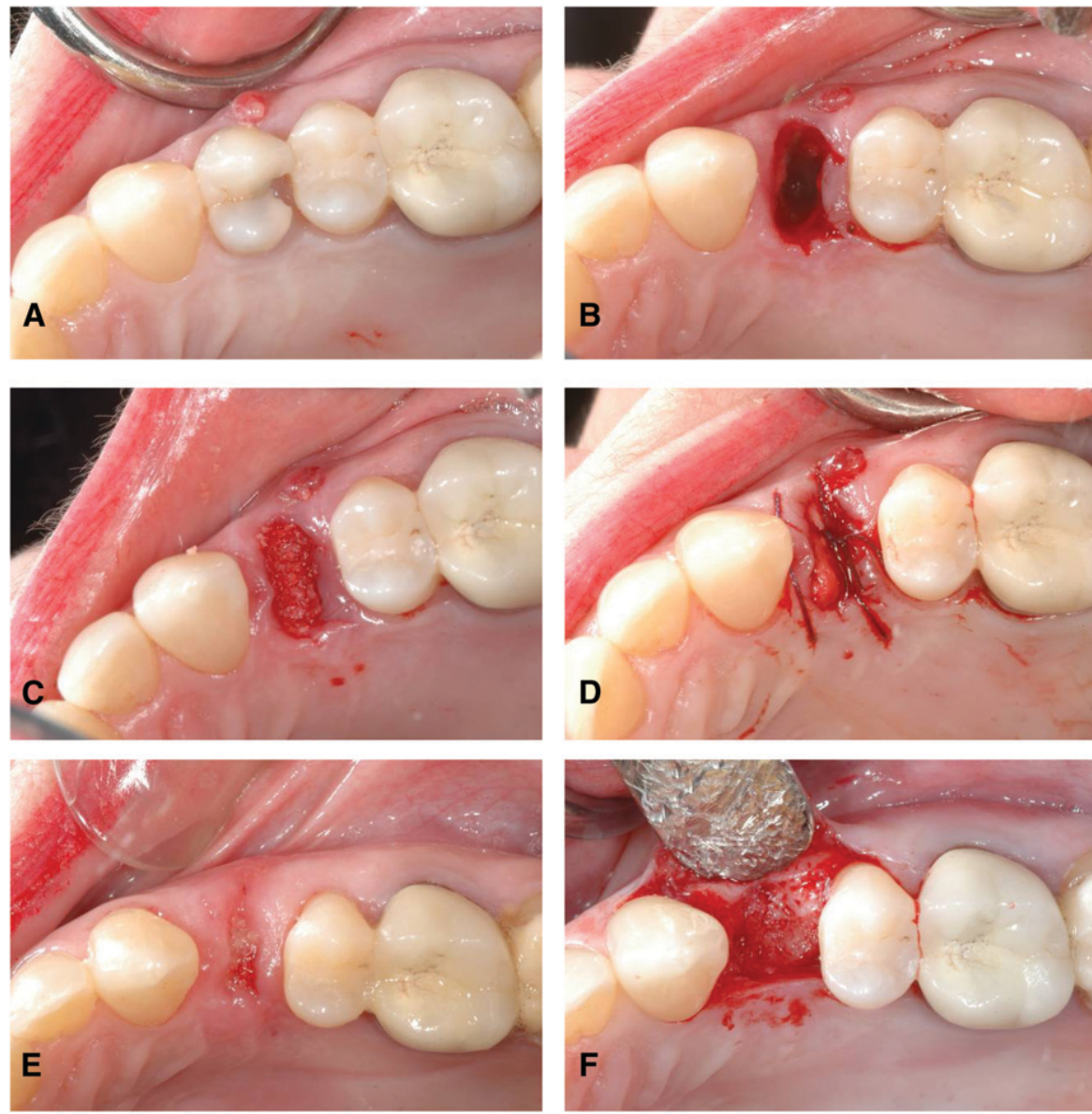

B
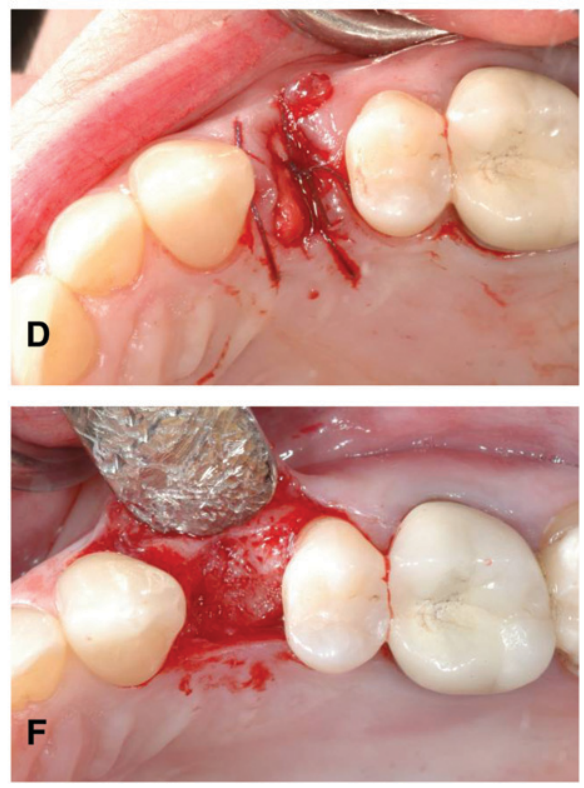

Figure I.

ADM treatment group. A) Hopeless maxillary premolar. B) Site after atraumatic extraction.

C) Socket filled with solvent-preserved mineralized cancellous allograft under light pressure.

D) Membrane trimmed and placed over bone graft. E) Postoperative 2-week healing. F) Site evaluation at 16 weeks.

the soft tissue socket was measured in the buccolingual and mesio-distal planes.

The extraction sockets were filled with solvent-preserved mineralized cancellous allograft ${ }^{\| I}$ using light pressure to prevent overcompaction. The socket was filled to the mesial and distal extraction socket bone walls. The vertical distance from the bone graft to the measuring stent was recorded. The membrane (PTFE or ADM) was trimmed to the shape and size of the extraction socket and passively placed over the bone graft. 4-0 sutures, 1 II in a cross-mattress style, were used to retain the membrane. At the end of the surgical procedure, a radiograph was taken using the custom radiographic device.

Amoxicillin (500 mg, three times a day for 7 days), or azithromycin (500 mg, every day for 3 days) for those allergic to penicillin, was prescribed to control infection. Postoperative pain was controlled using generic ibuprofen, $600 \mathrm{mg}$, three times a day, supplemented with narcotics, as needed. Patient instructions included no oral hygiene in the surgical area until the first postoperative appointment and a soft diet for 3 to 4 days.

Post-surgical appointments were scheduled at 2,4 , and 8 weeks after the socket-augmentation procedure. Health history updates, the patient's vital signs, PI, GI, and pain levels were assessed during each session, and plaque was removed from neighboring teeth. PTFE membranes were scheduled to be removed at the 4-week postoperative visit. After a healing time of 16 weeks, the socket-augmentation site was reevaluated, and data were collected. Then the patient was anesthetized,"\# and final research measurements were recorded. A standard implant surgical protocol was followed, with the elevation of a full-thickness flap directly over the extraction site. A trephine with an internal diameter of $2.75 \mathrm{~mm}$ was used to procure a $9-\mathrm{mm}$-long bone core specimen. The specimens were retrieved and placed in $10 \%$ neutral buffered formalin and stored. During the surgery, bone quality, ${ }^{32}$ classified as D1, D2, D3, or D4, was assessed and recorded. Biopsy specimens were dehydrated with a graded series of alcohols for 9 days. After dehydration, the specimens were infiltrated with a light-curing embedding resin. ** * After 20 days of infiltration with constant shaking at normal atmospheric pressure, the specimens were embedded and polymerized by $450 \mathrm{~nm}$ light, with the temperature of the specimens never exceeding $40^{\circ} \mathrm{C}$. The specimens were cut ${ }^{\dagger \dagger}$ to a thickness of $150 \mu \mathrm{m}$ using the technique described by Donath and Breuner ${ }^{33}$ and Rohrer and Schubert. ${ }^{34}$ Cores were polished to a thickness of 45 to $65 \mu \mathrm{m}$ using a series of polishing sandpaper disks from 800 to 2,400 grit, followed by a final polish with $0.3-\mu \mathrm{m}$ alumina polishing paste. The slides were stained with Stevenel's blue and Van Gieson's picro fuchsin and coverslipped for histologic analysis using bright field and polarized

\footnotetext{
I|| Puros, Zimmer Dental, Carlsbad, CA.

II Vicryl, Ethicon, Cornelia, GA.

\#\# 2\% lidocaine with 1:100,000 epinephrine, Carestream Health, Rochester, NY

*** Technovit 7200 VLC, Kulzer, Wehrheim, Germany.

$\dagger \dagger \dagger$ EXAKT Technologies, Oklahoma City, OK.
} 

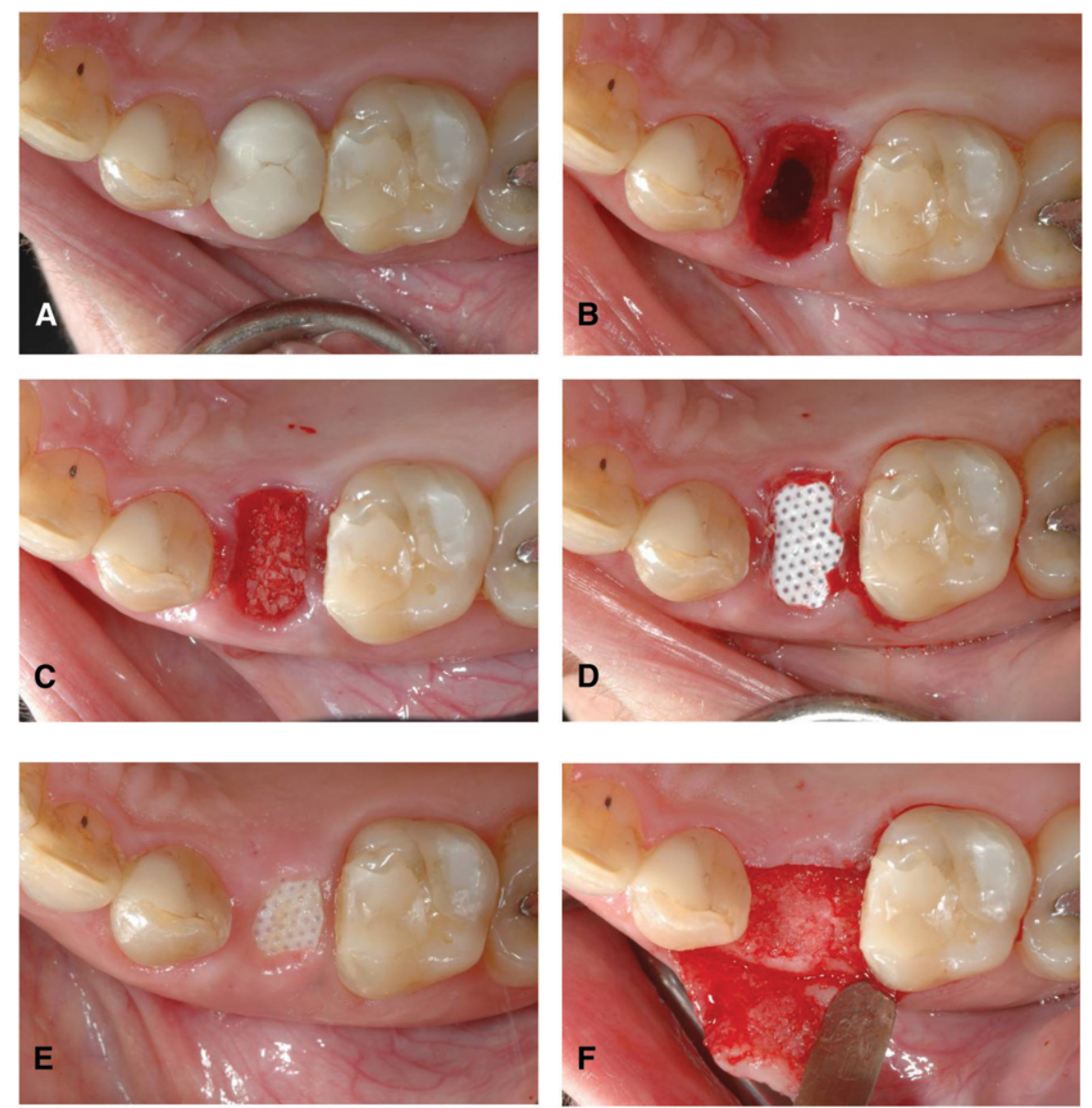

Figure 2.

PTFE treatment group. A) Hopeless maxillary premolar. B) Site after atraumatic extraction.

C) Socket filled with solvent-preserved mineralized cancellous allograft under light pressure.

D) Membrane trimmed and placed over bone graft. E) Postoperative 2-week healing. F) Site evaluation at 16 weeks.

microscopy. The cores were evaluated morphometrically after non-decalcified histologic preparation. All cores were digitized at the same magnification using a microscope $\mathrm{f}^{\ddagger}$ and a digital camera. $\S \S \S$ Histomorphometric measurements were completed using a combination of image software $\mathrm{Illl}^{\mathrm{l}}$ and the public domain image processing and analysis program. At least two slides from each core were evaluated for the percentages of new bone formation and residual graft material.

A multivariate analysis of variance, using the Wilks lambda analysis and $t$ test, was used to determine statistical significance at a level of $P<0.05$. Statistics were based on all cases with valid data for all variables in the model.

\section{RESULTS}

Twenty patients, ranging in age from 29 to 77 years, enrolled in the study ( $n=9$ for ADM and $n=11$ for PTFE); 18 patients completed the study. The study population was predominantly female $(n=13)$, and the mean patient age was similar in both groups ( 59 years for ADM and 55 years for PTFE). One patient from the ADM group was unable to continue with implant placement but did have final study measurements taken, and one patient from the PTFE group dropped out. For ease of calculations, only full data sets were used to calculate statistics, and patients who dropped out were not included in the histomorphometric statistical analysis.

The main reason for extraction was tooth fracture with an endodontic failure (13 of 19). Among the extracted teeth, there were one central incisor, three canines, eight first premolars, and seven second premolars.

Fifteen of 19 patients completed the study within the expected time frame, with an average healing time of 118 days $(\mathrm{ADM}=123 \pm 19$ days; $\mathrm{PTFE}=114 \pm 6$ days). Five males and 14 females presented for the 16 -week final evaluation. There were no major adverse events, although one patient complained of discomfort at the pretreatment evaluation and the 2-week postoperative visit. This was resolved by a prescribed antibiotic. None of the healing extraction sockets exfoliated any substantial amount of the bone graft, indicating that the membranes used were suitable for bone graft retention. The major deviation from the research protocol was that most PTFE membranes had perforated through the healing extraction socket soft tissue margin at the 2 -week postoperative visit, and all PTFE membranes exfoliated prematurely, prior to the 4-week postoperative appointment. The PTFE membranes covered the healing extraction socket for an average of 16.6 days.

A minor difference in the extraction socket dimensions existed between the two study groups at baseline. The average bucco-lingual socket width was $7.8 \mathrm{~mm}$ versus $7.2 \mathrm{~mm}$, whereas the average mesiodistal socket width was $5.2 \mathrm{~mm}$ versus $5.0 \mathrm{~mm}$

㧊 Zeiss Axiolab, Carl Zeiss Microimaging, Thornwood, NJ. $\S \S \S$ Nikon Coolpix 4500, Nikon, Melville, NY.

\|l\|l Adobe PhotoShop, Adobe Systems, San Jose, CA. 
for ADM and PTFE, respectively. Minor differences were observed in the quantity of KG $(5.2 \mathrm{~mm}$ versus $4.6 \mathrm{~mm}$ for ADM and PTFE, respectively). The keratinized tissue dimension was not evaluated at the 16 week follow-up because it was measured from the free gingival margin and not a reference point. After tooth extraction, three patients from the ADM group were lacking a buccal plate, only in the mid-buccal position, at $5 \mathrm{~mm}$ apical to the buccal free gingival margin. These patients did not provide any data for buccal bone plate thickness, but their data were used to calculate horizontal alveolar ridge change. The buccal bone plate, measured at $5 \mathrm{~mm}$ from the free gingival margin, was 1.3 and $1.6 \mathrm{~mm}$ in the ADM and PTFE groups, respectively.

\section{Surgical Reevaluation}

At the 16 -week reevaluation, 18 patients proceeded with the study protocol and had an implant placed in addition to a bone core biopsy. Surgical protocol allowed for placement of 18 implants: 16 were $4.0 \mathrm{~mm}$ in diameter and two were $4.1 \mathrm{~mm}$ in diameter. The average baseline stent-buccal plate measurements were 4.00 and $3.80 \mathrm{~mm}$, whereas at 16 weeks they were 4.44 and $4.10 \mathrm{~mm}$ for ADM and PTFE, respectively (Table 1 ). The 16 -week healing period produced a loss in buccal plate width of 0.44 and 0.30 $\mathrm{mm}$ for ADM and PTFE, respectively. Although differences between the baseline and 16-week evaluations were statistically significant for both groups $(P=$ 0.020 ), no statistically significant difference was found between the two treatment modalities $(P=$ 0.626).

Vertical alveolar crest changes were also evaluated (Table 1). An average vertical loss of 1.11 and 0.25 $\mathrm{mm}$ was found for ADM and PTFE, respectively. A sig- nificant change from the baseline measurements to the 16-week evaluation was found for both treatment modalities $(P=0.008)$; however, no difference $(P=$ 0.074 ) was noted between the groups.

Soft tissue changes during the 16-week healing stage also revealed a trend (Table 2). Although the buccal soft tissue thickness changed over time, no statistically significant difference was observed between the two treatment modalities $(P=0.280)$. A significant difference was found between the pre- and post-treatment buccal soft tissue thickness $(P=$ 0.046) as a result of the tooth extraction.

Bone cores biopsies were taken from the actual implant osteotomy during implant site preparation, which allowed for the assessment of bone quality. The ADM group had two sites with D2 bone quality, five sites with D3 bone quality, and one site with D4 bone quality, whereas the PTFE group had four sites with D2 bone quality and five sites with D3 bone quality. The bone-quality assessments were done using the classification of Misch. ${ }^{32}$ The ADM group had a mean bone quality of D2.9, whereas it was D2.6 in the PTFE group.

\section{Histomorphometric Analysis}

The bone cores revealed a mixture of vital bone, nonvital bone, and marrow/fibrous tissue in all samples (Fig. 3; Table 3). A closer analysis of the obtained cores revealed $41.81 \%$ (range, $29.99 \%$ to $56.39 \%$ ) and $47.36 \%$ (range, $26.20 \%$ to $64.85 \%$ ) bone in ADM and PTFE groups, respectively. The remaining component of the bone cores was marrow/fibrous tissue, which accounted for $58.19 \%$ (range, $43.61 \%$ to $70.01 \%$ ) in the ADM group and $52.64 \%$ (range, $35.15 \%$ to $73.80 \%$ ) in the PTFE group. Statistical analysis of these data did not show any significant

Table I.

\section{Alveolar Ridge Dimensional Changes (mm)}

\begin{tabular}{|c|c|c|c|c|c|c|c|c|}
\hline & \multicolumn{4}{|c|}{ Stent to Buccal Plate } & \multicolumn{4}{|c|}{ Stent to Crest } \\
\hline & \multicolumn{2}{|c|}{ ADM } & \multicolumn{2}{|c|}{ PTFE } & \multicolumn{2}{|c|}{ ADM } & \multicolumn{2}{|c|}{ PTFE } \\
\hline & Pre-Tx & Post-Tx & Pre-Tx & Post-Tx & Pre-Tx & Post-Tx & Pre-Tx & Post-Tx \\
\hline Mean & 4.00 & 4.44 & 3.80 & 4.10 & 8.39 & 9.50 & 8.15 & 8.40 \\
\hline SD & 0.40 & 0.58 & 0.90 & 0.74 & 2.15 & 3.05 & 1.81 & 1.68 \\
\hline Difference & \multicolumn{2}{|c|}{0.44} & \multicolumn{2}{|c|}{0.30} & \multicolumn{2}{|c|}{ I.I } & \multicolumn{2}{|c|}{0.25} \\
\hline$p^{*}$ & \multicolumn{2}{|c|}{0.020} & \multicolumn{2}{|c|}{0.020} & \multicolumn{2}{|c|}{0.008} & \multicolumn{2}{|c|}{0.008} \\
\hline$p^{\dagger}$ & \multicolumn{4}{|c|}{0.626} & \multicolumn{4}{|c|}{0.074} \\
\hline
\end{tabular}

Tx $=$ treatment.

* Pretreatment versus post-treatment.

$\dagger$ ADM versus PTFE. 
Table 2.

\section{Buccal Soft Tissue Dimensions (mm)}

\begin{tabular}{|c|c|c|c|c|c|c|}
\hline & \multicolumn{3}{|c|}{ ADM } & \multicolumn{3}{|c|}{ PTFE } \\
\hline & \multicolumn{2}{|c|}{ Soft Tissue Thickness } & \multirow[b]{2}{*}{ KG } & \multicolumn{2}{|c|}{ Soft Tissue Thickness } & \multirow[b]{2}{*}{$K G$} \\
\hline & Pre-Tx & Post-Tx & & Pre-Tx & Post-Tx & \\
\hline Mean & 1.06 & 1.00 & 4.6 & 1.08 & 0.91 & 5.2 \\
\hline SD & 0.24 & 0.24 & 1.3 & 0.24 & 0.22 & 1.2 \\
\hline p* & \multicolumn{2}{|c|}{0.046} & & \multicolumn{2}{|c|}{0.046} & \\
\hline$p^{\dagger}$ & \multicolumn{5}{|c|}{0.280} & \\
\hline
\end{tabular}

Tx $=$ treatment.

* Pretreatment versus post-treatment.

$\dagger$ ADM versus PTFE.
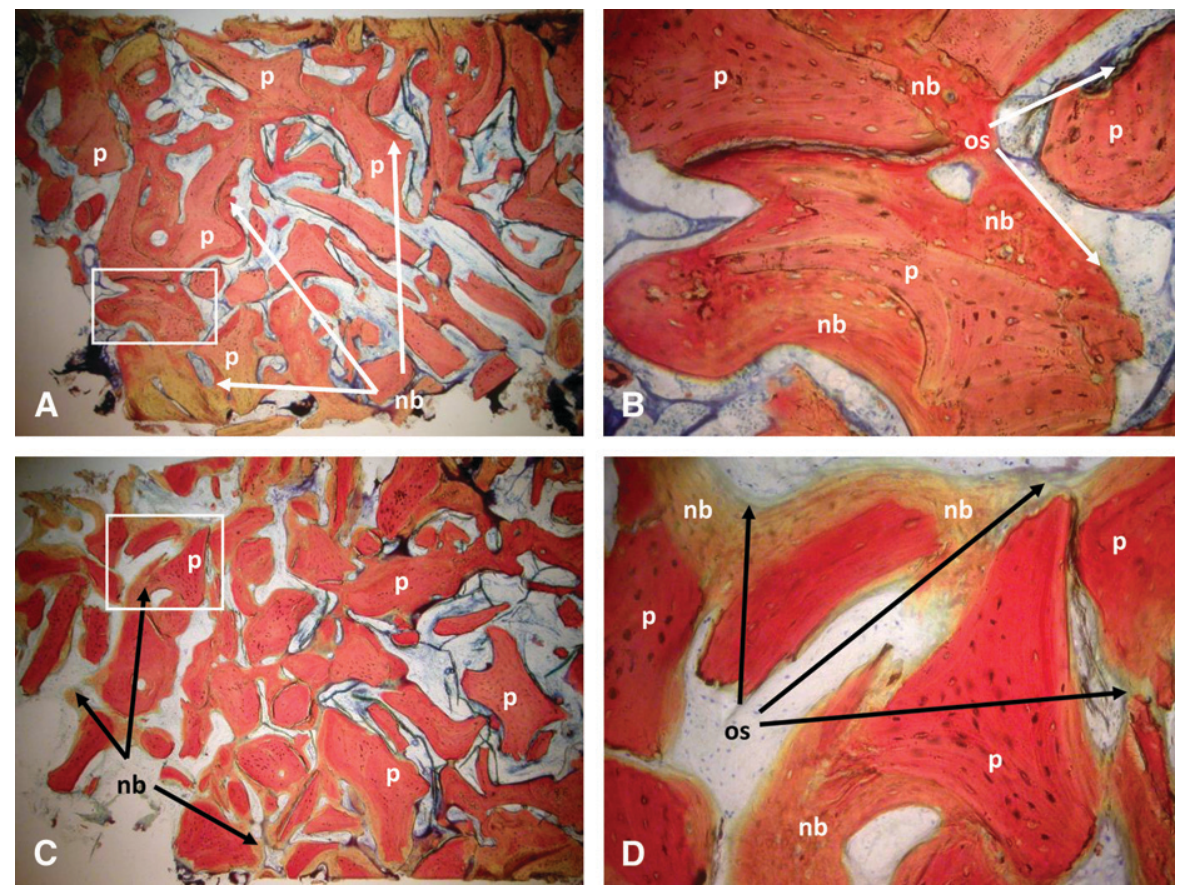

Figure 3.

Histology of bone cores. $\boldsymbol{A})$ Bone core specimen from ADM group showing allograft particles ( $P$ ) with new bone ( $n b)$ formation in its surface. B) Magnified view of rectangle in A. C) Bone core specimen from PTFE group showing allograft particles ( $p$ ) with new bone ( $n b)$ formation in its surface. D) Magnified view of rectangle in C. Calcified bone stained bright red with variations in intensity depending on the maturity of the bone. Non-calcified bone and osteoid (os) stained bright green; osteoblasts stained blue. (Stevenel's blue and Van Gieson's picro fuchsin; original magnification: $A$ and $C, \times 40 ; B$ and $D, \times 200$.)

differences between the two treatment groups $(P=$ 0.252). Vital bone quantity favored the PTFE membrane group: $68.89 \%$ (range, $37.83 \%$ to $85.18 \%$ ) and $66.69 \%$ (range, $41.99 \%$ to $93.32 \%$ ) for PTFE and ADM groups, respectively. Although different, no statistical significance was found within this data set $(P=0.782)$. Remaining particulate bone allograft quantity was also higher in the PTFE membrane group: $14.73 \%$ versus $13.93 \%$. Again, no statistical significance was found $(P=0.782)$. The histomorphometric slides clearly depicted allograft remnants being covered largely by vital bone (new bone) and to a lesser degree by marrow/soft tissue.

\section{DISCUSSION}

Recent changes in implant therapy and evaluation of the implant site have resulted in a modification of the success criteria of Albrektsson et al. ${ }^{35}$ to include an esthetic outcome. For an implant to remain successful over time, an intact buccal bone plate is necessary to maintain a bony wall and soft tissue drape. This bone plate thickness was determined by Spray et al. ${ }^{36}$ to be $\geq 1.8 \mathrm{~mm}$ thick to preserve the buccal plate height and soft tissue margin and prevent future tissue loss. Therefore, it is critical to maintain the buccal bone integrity at all stages, from tooth extraction to final implant restoration. As a precautionary measure and means of having sufficient buccal bone, some clinicians ${ }^{37}$ proposed placing an immediate implant as much as $3 \mathrm{~mm}$ lingual to the buccal plate. A more efficient and predictable way to control the implant buccal bone thickness is to place the implant into a healed grafted extraction socket. 
Table 3.

Histomorphometric Analysis

\begin{tabular}{lccccccccc}
\hline & \multicolumn{2}{c}{ Bone (\%) } & \multicolumn{2}{c}{ New Bone (\%) } & \multicolumn{2}{c}{ Particle (\%) } & \multicolumn{2}{c}{ Marrow/Soft Tissue (\%) } \\
\cline { 2 - 10 } & ADM & PTFE & ADM & PTFE & ADM & PTFE & ADM & PTFE \\
\hline Mean & 41.81 & 47.36 & 66.69 & 68.89 & 33.31 & 31.11 & 58.19 & 52.64 \\
Percentage of core & 41.81 & 47.36 & 27.89 & 32.63 & 13.93 & 14.73 & 58.19 & 52.64 \\
$P$ & \multicolumn{2}{c}{0.252} & \multicolumn{2}{c}{0.782} & \multicolumn{2}{c}{0.782} & & 0.252 \\
\hline
\end{tabular}

This study examined the alveolar dimensional changes after tooth extraction. As with all human studies, patient compliance is critical, yet very often unpredictable. Looking at the study population, females showed a greater tendency toward compliance, as reported in the literature, ${ }^{38}$ in staying within the research protocol timeline. Nonetheless, treatment outcomes might be hindered by the lack of patient compliance. Two patients (one each from ADM and PTFE groups) did not complete the histomorphometric analysis. In addition, all three patients whose buccal plate dehiscences could not be evaluated because of the lack of buccal bone at $5 \mathrm{~mm}$ apical to the free gingival margin were in the ADM group. This modified the patient proportions to 10 PTFE and six ADM when performing some data analyses. Although three ADM sites had an original buccal dehiscence, the healed sites did not differ significantly from those of the PTFE or ADM group with an intact buccal plate. It would be interesting to compare these sites to the traditional healing pattern of an extraction socket.

All extraction sites healed well without any complications. The alveolar ridges obtained by the end of the healing stage were wide enough to accept regular-diameter implants. The allograft material was retained in all extraction sockets with no significant exfoliation; both membranes used acted as graft barriers rather than traditional regenerative membranes. The allograft used was an appropriate material because it allowed for extraction sockets to heal adequately, and it preserved the alveolar ridge dimensions. The reason for choosing PTFE instead of expanded PTFE is because many clinicians were using the PTFE membrane for this type of treatment without evidence. Hence, it is our hope that this article presents some insight about this approach. Additionally, the reasons for choosing the PTFE membrane were its low porosity (non-expanded nature, which creates bacteria-incorporation resistance), limited surgical area, conservation of soft tissue architecture, and prevention of soft tissue in-growth. Bartee ${ }^{39,40}$ reported that when PTFE was used for socket augmentation, well-vascularized bone free of fibrosis or chronic inflammation was observed; some remaining demineralized freezedried bone allograft and calcium phosphate particles demarcated newly formed bone from donor bone. However, there are some concerns with the use of PTFE membranes. By week 2, all PTFE membranes perforated the soft tissue margin; all membranes were exfoliated by 28 days (Fig. 2). This may lead to premature infringement of the extraction socket by the advancing soft tissue if no bone was placed or if bone graft was exfoliated. Another critique could come from the fact that the free gingival margin was never isolated from the grafted extraction socket by the membrane, meaning that the tested membranes functioned as a dressing rather than as a membrane barrier. Nonetheless, histomorphometric analysis revealed that premature soft tissue migration did not seem to pose a problem or interfere with bone fill. Therefore, it might be speculated that the main indication of membrane use in socket augmentation is to prevent particulate bone graft loss during the early stages of healing.

Buccal bone changes that occur after extraction are largely due to the presence of bundle bone in the crestal region. ${ }^{41}$ Bundle bone loss expresses itself largely as horizontal alveolar ridge dimension change. The soft tissue that covers this area also showed a tendency to undergo dimensional changes during the 16 -week healing period in our study. The pre- and posttreatment changes, although very small, were of statistical significance; however, there was no difference in soft tissue change between the two treatment groups. The question that should be addressed is whether these changes are of any clinical significance. Soft tissue thickness was measured using the UNC probe and a measuring stent. The problem associated with this technique is that the soft tissue is perforated with an instrument that is $\sim 0.7 \mathrm{~mm}$ thick and has a blunt end. The pressure exerted on the soft tissue creates buckling of the gingiva underneath the probe until perforation occurs. However, the tissue does not return to its normal state after perforation; it remains buckled under tension. This may not be a reliable method for assessing thickness. The other problem 
with this technique is the measuring scale used. The periodontal probe used has $1-\mathrm{mm}$ increments. The soft tissue examined was 0.5 to $2.0 \mathrm{~mm}$ thick, which is within the measuring error of the probe. We must be very prudent in drawing any conclusions from the soft tissue data. Further differences in the soft tissue profiles were seen during flap elevation. The healing process expected with the ADM membrane included incorporation of the membrane (Fig. 1) into the soft tissues, with a potential increase in gingival thickness. ${ }^{42}$ This incorporation potentially alters the gingival matrix. During flap elevation, it was observed that all sites covered with ADM had a depressed center where the extracted tooth used to be; this area was spongier than the surrounding gingiva. Because the spongy area also corresponded to the place of abutment emergence, the spongy gingiva was usually trimmed prior to placement of the healing abutment. It would have been interesting to evaluate this soft tissue histologically and compare it to sites that healed naturally and to those in which ADM was used to augment the soft tissue drape, possibly by using a flapless approach during bone core biopsy harvesting.

Histomorphometric analysis provided further insight into the healing process of the solvent-preserved mineralized cancellous allograft; $14.3 \%$ of the particulate graft remained after 16 weeks of healing. This result was similar to numerous studies showing that full graft resorption was never observed. In fact, these data were superior to those of Artzi et al., ${ }^{7}$ who reported 30\% graft remaining. Two major differences were noted between our study and the one by Artzi et al.: they used a xenograft and allowed a longer healing period ( 9 months). Yet, even with this longer healing time, a major component of the particulate xenograft remained. Similarly, Carmagnola et al. ${ }^{43}$ found a significant proportion of xenograft particles $(21.1 \%)$ remaining. This slower resorption rate could hinder new bone formation as shown by Vance et al.; ${ }^{25}$ vital bone was found in $61 \%$ of sites grafted with an allograft versus $26 \%$ of sites grafted with a bovine hydroxyapatite. The results observed were slightly inferior to those of Wang and Tsao, ${ }^{24}$ who reported $68.5 \%$ new bone formation and only $4.8 \%$ remaining bone graft. Although Wang and Tsao's ${ }^{24}$ study used the same allograft material as this study, the healing time was 5 to 6 months. It could be assumed that if a longer healing period was allowed in this study, more graft resorption would have been observed, and more vital bone would have been found. In line with Wang and Tsao's ${ }^{24}$ research, the present study showed that solvent-preserved mineralized cancellous allograft was embedded mainly by vital bone, unlike the bovine-derived graft, which showed limited vital bone contact. The staining technique used in this study is a possible alternate explanation for the difference in vital bone found compared to that reported by Wang and Tsao. ${ }^{24}$ Thompson et al. ${ }^{44}$ indicated that an error could be easily introduced because the new bone and remaining particles both stain red, making it difficult for a computer to distinguish between the two. The investigator must differentiate between redstained vital and non-vital bone and delineate a boundary between these two for standardized computer image analysis. Because bone vitality is not easily recognized, an error could be introduced into the computation by incorrectly identifying the two bone types.

Early extraction socket healing is expected to decrease the alveolar ridge by 2 to $4 \mathrm{~mm}$ horizontally and $1 \mathrm{~mm}$ vertically. ${ }^{6,27,45}$ This change is time dependent; by the end of the first year postextraction, nearly $6 \mathrm{~mm}$ of buccal loss can be expected. ${ }^{46}$ The changes observed in this study were much lower: 0.3 to 0.44 $\mathrm{mm}$ in the horizontal dimension and 0.25 to $1.1 \mathrm{~mm}$ in the vertical dimension, with both groups having an average initial buccal bone plate thickness of 1.3 to $1.6 \mathrm{~mm}$. The minimal horizontal change allowed for proper implant placement. The data are superior to several studies ${ }^{10,25,27,45}$ in which horizontal bone loss of 0.5 to $1.3 \mathrm{~mm}$ was observed. However, the vertical changes were not as impressive; a single patient experienced a 3-mm change, which skewed the average. This was largely due to a root fracture of a canine tooth that was removed only after considerable trauma.

\section{CONCLUSIONS}

This study supports the evidence that socket augmentation cannot prevent bone loss, but it limits bone resorption. Further investigations that include a negative control (e.g., solvent-preserved mineralized cancellous allograft alone) and a larger sample size would give more strength to the findings of this study.

\section{ACKNOWLEDGMENTS}

The authors thank Dr. Jeffrey Shotwell, Department of Prosthodontics, University of Michigan, for his help with the prosthetic restoration of all study subjects. We also thank Drs. Michael Rohrer and Hari Prasad for their help with the core biopsy analysis at the University of Minnesota Hard Tissue Research Laboratory, Minneapolis, Minnesota. This study was supported, in part, by a research grant from BioHorizons, Birmingham, Alabama. Osteogenics Biomedical, Lubbock, Texas, donated the PTFE membrane used in this study. The University of Michigan Graduate Periodontics Student Research Fund provided additional support for the completion of this study. The authors report no conflicts of interest related to this study. 


\section{REFERENCES}

1. Sclar AG. Preserving alveolar ridge anatomy following tooth removal in conjunction with immediate implant placement. The Bio-Col technique. Atlas Oral Maxillofac Surg Clin North Am 1999;7:39-59.

2. Sclar AG. Strategies for management of single-tooth extraction sites in aesthetic implant therapy. $J$ Oral Maxillofac Surg 2004;62:90-105.

3. Wang HL, Kiyonobu K, Neiva RF. Socket augmentation: Rationale and technique. Implant Dent 2004; 13:286-296.

4. Neiva RF, Tsao YP, Eber R, Shotwell J, Billy E, Wang HL. Effects of a putty-form hydroxyapatite matrix combined with the synthetic cell-binding peptide P-15 on alveolar ridge preservation. J Periodontol 2008;79: 291-299.

5. Darby I, Chen S, De Poi R. Ridge preservation: What is it and when should it be considered. Aust Dent $J$ 2008;53:11-21.

6. Lekovic V, Kenney EB, Weinlaender M, et al. A bone regenerative approach to alveolar ridge maintenance following tooth extraction. Report of 10 cases. J Periodontol 1997;68:563-570.

7. Artzi Z, Tal H, Dayan D. Porous bovine bone mineral in healing of human extraction sockets. Part 1: Histomorphometric evaluations at 9 months. J Periodontol 2000;71:1015-1023.

8. Nemcovsky CE, Serfaty V. Alveolar ridge preservation following extraction of maxillary anterior teeth. Report on 23 consecutive cases. J Periodontol 1996;67:390395.

9. Wang HL, Tsao YP. Histologic evaluation of socket augmentation with mineralized human allograft. Int $J$ Periodontics Restorative Dent 2008;28:231237.

10. Zubillaga G, Von Hagen S, Simon BI, Deasy MJ. Changes in alveolar bone height and width following post-extraction ridge augmentation using a fixed bioabsorbable membrane and demineralized freeze-dried bone osteoinductive graft. J Periodontol 2003;74:965975.

11. Nevins $M$, Camelo $M$, De Paoli S, et al. A study of the fate of the buccal wall of extraction sockets of teeth with prominent roots. Int $J$ Periodontics Restorative Dent 2006;26:19-29.

12. Skoglund A, Hising P, Young C. A clinical and histologic examination in humans of the osseous response to implanted natural bone mineral. Int J Oral Maxillofac Implants 1997;12:194-199.

13. Nevins M, Giannobile WV, McGuire MK, et al. Plateletderived growth factor stimulates bone fill and rate of attachment level gain: Results of a large multicenter randomized controlled trial. J Periodontol 2005;76: 2205-2215.

14. Scarborough NL, White EM, Hughes JV, Manrique AJ, Poser JW. Allograft safety: Viral inactivation with bone demineralization. Contemp Orthop 1995;31: 257-261.

15. Buck BE, Malinin TI, Brown MD. Bone transplantation and human immunodeficiency virus. An estimate of risk of acquired immunodeficiency syndrome (AIDS). Clin Orthop Relat Res 1989;129-136.

16. Mellonig JT, Prewett AB, Moyer MP. HIV inactivation in a bone allograft. J Periodontol 1992;63:979-983.

17. Tsao YP, Neiva R, Al-Shammari K, Oh TJ, Wang HL. Effects of a mineralized human cancellous bone allo- graft in regeneration of mandibular Class II furcation defects. J Periodontol 2006;77:416-425.

18. Vastardis S, Yukna RA. Evaluation of allogeneic bone graft substitute for treatment of periodontal osseous defects: 6-month clinical results. Compend Contin Educ Dent 2006;27:38-44.

19. Gapski R, Neiva R, Oh TJ, Wang HL. Histologic analyses of human mineralized bone grafting material in sinus elevation procedures: A case series. Int $J$ Periodontics Restorative Dent 2006;26:59-69.

20. Froum SJ, Wallace SS, Elian N, Cho SC, Tarnow DP. Comparison of mineralized cancellous bone allograft (Puros) and anorganic bovine bone matrix (Bio-Oss) for sinus augmentation: Histomorphometry at 26 to 32 weeks after grafting. Int $J$ Periodontics Restorative Dent 2006;26:543-551.

21. Leonetti JA, Koup R. Localized maxillary ridge augmentation with a block allograft for dental implant placement: Case reports. Implant Dent 2003;12:217226.

22. Park SH, Wang HL. Management of localized buccal dehiscence defect with allografts and acellular dermal matrix. Int $J$ Periodontics Restorative Dent 2006;26: 589-595.

23. Minichetti JC, D'Amore JC, Hong AY, Cleveland DB. Human histologic analysis of mineralized bone allograft (Puros) placement before implant surgery. J Oral Implantol 2004;30:74-82.

24. Wang HL, Tsao YP. Mineralized bone allograft-plug socket augmentation: Rationale and technique. Implant Dent 2007; 16:33-41.

25. Vance GS, Greenwell H, Miller RL, Hill M, Johnston H, Scheetz JP. Comparison of an allograft in an experimental putty carrier and a bovine-derived xenograft used in ridge preservation: A clinical and histologic study in humans. Int $J$ Oral Maxillofac Implants 2004;19:491-497.

26. Fowler EB, Breault LG, Rebitski G. Ridge preservation utilizing an acellular dermal allograft and demineralized freeze-dried bone allograft: Part I. A report of 2 cases. J Periodontol 2000;71:1353-1359.

27. Iasella JM, Greenwell H, Miller RL, et al. Ridge preservation with freeze-dried bone allograft and a collagen membrane compared to extraction alone for implant site development: A clinical and histologic study in humans. J Periodontol 2003;74:990-999.

28. Luczyszyn SM, Papalexiou V, Novaes AB Jr., Grisi MF, Souza SL, Taba M Jr. Acellular dermal matrix and hydroxyapatite in prevention of ridge deformities after tooth extraction. Implant Dent 2005;14:176-184.

29. Landsberg CJ, Bichacho N. A modified surgical/prosthetic approach for optimal single implant supported crown. Part I - The socket seal surgery. Pract Periodontics Aesthet Dent 1994;6:11-17.

30. Misch CE, Dietsh-Misch F, Misch CM. A modified socket seal surgery with composite graft approach. J Oral Implantol 1999;25:244-250.

31. Löe $H$. The gingival index, the plaque index and the retention index systems. J Periodontol 1967; 38(Suppl.):610-616.

32. Misch CE. Divisions of available bone in implant dentistry. Int J Oral Implantol 1990;7:9-17.

33. Donath K, Breuner G. A method for the study of undecalcified bones and teeth with attached soft tissues. The Sage-Schliff (sawing and grinding) technique. J Oral Pathol 1982;11:318-326. 
34. Rohrer MD, Schubert CC. The cutting-grinding technique for histologic preparation of undecalcified bone and bone-anchored implants. Improvements in instrumentation and procedures. Oral Surg Oral Med Oral Pathol 1992;74:73-78.

35. Albrektsson T, Zarb G, Worthington P, Eriksson AR. The long-term efficacy of currently used dental implants: A review and proposed criteria of success. Int $J$ Oral Maxillofac Implants 1986;1:11-25.

36. Spray JR, Black CG, Morris HF, Ochi S. The influence of bone thickness on facial marginal bone response: Stage 1 placement through stage 2 uncovering. Ann Periodontol 2000;5:119-128.

37. Froum SJ, Cho SC, Francisco H, Park YS, Elian N, Tarnow DP. Immediate implant placement and provisionalization - Two case reports. Pract Proced Aesthet Dent 2007;19:621-628.

38. Galgut PN. Compliance with maintenance therapy after periodontal treatment. Dent Health (London) 1991; 30:3-7.

39. Bartee BK. Extraction site reconstruction for alveolar ridge preservation. Part 2: Membrane-assisted surgical technique. J Oral Implantol 2001;27:194-197.

40. Bartee BK. Evaluation of a new polytetrafluoroethylene guided tissue regeneration membrane in healing extraction sites. Compend Contin Educ Dent 1998; 19:1256-1258, 1260, 1262-1264.

41. Araujo MG, Lindhe J. Dimensional ridge alterations following tooth extraction. An experimental study in the dog. J Clin Periodontol 2005;32:212-218.
42. Woodyard JG, Greenwell H, Hill M, Drisko C, Iasella JM, Scheetz J. The clinical effect of acellular dermal matrix on gingival thickness and root coverage compared to coronally positioned flap alone. J Periodontol 2004;75:44-56.

43. Carmagnola D, Adriaens P, Berglundh T. Healing of human extraction sockets filled with Bio-Oss. Clin Oral Implants Res 2003;14:137-143.

44. Thompson DM, Rohrer MD, Prasad HS. Comparison of bone grafting materials in human extraction sockets: Clinical, histologic, and histomorphometric evaluations. Implant Dent 2006;15:89-96.

45. Lekovic V, Camargo PM, Klokkevold PR, et al. Preservation of alveolar bone in extraction sockets using bioabsorbable membranes. J Periodontol 1998;69: 1044-1049.

46. Schropp L, Wenzel A, Kostopoulos L, Karring T. Bone healing and soft tissue contour changes following single-tooth extraction: A clinical and radiographic 12-month prospective study. Int J Periodontics Restorative Dent 2003;23:313-323.

Correspondence: Dr. Hom-Lay Wang, Department of Periodontics and Oral Medicine, School of Dentistry, University of Michigan, 1011 N. University, Ann Arbor, MI 48109-1078. Fax: 734/936-0374; e-mail: homlay@ umich.edu.

Submitted October 10, 2008; accepted for publication January 7, 2009. 